\title{
Immortality time and serial myocardial perfusion imaging: Only those who do not die may repeat the exam
}

\author{
Mario Petretta, $M D,{ }^{a}$ Marco Salvatore, $M D,{ }^{b}$ and Alberto Cuocolo, $M^{c}$ \\ a Department of Translational Medical Sciences, University Federico II, Naples, Italy \\ ${ }^{b}$ IRCCS SDN, Naples, Italy \\ c Department of Advanced Biomedical Sciences, University Federico II, Naples, Italy
}

Received Apr 29, 2015; accepted Apr 29, 2015

doi:10.1007/s12350-015-0171-y

\section{See related article, pp. 101-112}

\section{PREDICTION IS VERY DIFFICULT, ESPECIALLY IF IT IS ABOUT THE FUTURE (NIELS BOHR)}

Assessment of risk of future events in patients with suspected or known coronary artery disease (CAD) is challenging. Many studies are published every month on prognostic factors, and novel prognostic models and flowchart are proposed for clinical use. A quantity of data accumulated since the 70' demonstrates the strength of stress single-photon emission-computed tomography myocardial perfusion imaging (MPI) in predicting outcome. ${ }^{1,2}$ MPI is also commonly used as a gatekeeper to select patients for coronary revascularization. ${ }^{3,4}$ The degree of left ventricular (LV) dysfunction and the extent and magnitude of inducible myocardial ischemia are important prognostic variables that can be assessed by MPI. Transient ischemic LV cavity dilation is another high-risk variable associated with the presence of severe angiographic $\mathrm{CAD}^{5}$ and with an adverse outcome. ${ }^{6,7}$ Serial MPI imaging has been used to compare the effectiveness of intercurrent treatments, within the framework of randomized controlled trials. ${ }^{8-10}$ Moreover, an analysis of the Detection of Ischemia in Asymptomatic Diabetics (DIAD) study not including patients with intervening cardiac events or revascularization found unexpected resolution of ischemia in most of these

Reprint requests: Alberto Cuocolo, MD, Department of Advanced Biomedical Sciences, University Federico II, Naples, Italy; cuocolo@unina.it

J Nucl Cardiol 2016;23:113-6.

$1071-3581 / \$ 34.00$

Copyright (c) 2015 American Society of Nuclear Cardiology. patients, potentially because of more aggressive medical treatment of cardiovascular risk factors. ${ }^{11}$

\section{PROGNOSTIC VALUE OF REGADENOSON MPI}

Regadenoson is the first selective adenosine $A_{2 A}$ receptor agonist approved by the Food and Drug Administration and is the most widely used stress agent for MPI in the United States. It has many of the characteristics of an ideal stress perfusion agent, being a potent and a selective coronary vasodilator with a rapid onset of action, a short duration of action, and being administered as a fixed-dose bolus (not weight-based). Further, it has a good safety and tolerability profile including in patients with reactive airway disease, and its side effects can be readily reversed by an antagonist if needed. ${ }^{12}$ The diagnostic accuracy of regadenoson is comparable to adenosine MPI. ${ }^{13}$ Regadenoson MPI also provide powerful prognostic information that has important implications in patient management and can guide clinical practice. ${ }^{14}$ Hage et $\mathrm{al}^{15}$ categorized 1400 patients (42\% male, 37\% diabetes, $21 \%$ heart failure, $26 \%$ end-stage renal disease) based on the perfusion defect size (PDS) using automated quantitative analysis. The primary outcome was a composite of cardiac death, myocardial infarction, and late coronary revascularization ( $>90$ days after MPI). The primary outcome occurred in $23 \%$ of the patients during $46 \pm 18$ months of follow-up and $8 \%$ had early coronary revascularization (within 90 days of MPI). In an adjusted Cox proportional model, the hazard ratio for the primary outcome progressively increased with the extent of PDS.

\section{SERIAL MPI STUDIES AND PROGNOSIS}

The prognostic significance of serial change of imaging parameters has been previously reported. ${ }^{16-18}$ Iskandrian et $\mathrm{al}^{19}$ in a landmark study first 
comprehensively reviewed where serial MPI might be useful clinically and in research studies. They also highlighted strategies for addressing the various issues that are unique to serial testing in order to derive more valid and robust data from the serial scans. In fact, criteria for defining a real MPI change in an individual patient beyond variability are paramount to interpret and use information from serial testing. In this issue of the Journal, El-Hajj et al ${ }^{20}$ evaluated the effect of changes in PDS and LV ejection fraction (EF) during serial myocardial perfusion imaging on cardiovascular outcomes in high-risk patients. The authors retrospectively evaluated 698 patients (61 \pm 11 years, $53 \%$ male) who underwent two regadenoson MPI studies within $16 \pm 9$ months for clinical indications. Patients were stratified into 3 groups: group 1 included patients with normal perfusion on MPI-1 and MPI-2; group 2 included patients with abnormal perfusion on MPI- 1 and with improvement ( $\geq 5 \%$ decrease in PDS) on MPI-2; group 3 included patients with abnormal perfusion on MPI-1 and with either no improvement ( $<5 \%$ change) or worsening $(\geq 5 \%$ increase in PDS) on MPI-2 and patients with normal perfusion on MPI-1 and abnormal perfusion on MPI-2. Changes in PDS and EF on serial MPI studies provided incremental prognostic information to initial and follow-up MPI findings. A new perfusion abnormality or an increase in PDS and a drop in LVEF identified high-risk patients. In the period between the 2 MPI studies, $80(12 \%)$ patients underwent coronary revascularization: most of these patients were in group 2. The primary endpoint was a composite of all-cause death, non-fatal myocardial infarction or coronary revascularization after the second MPI. During $24 \pm 16$ months of follow-up after the second MPI, the primary outcome occurred in 167 (24\%) patients $(8 \%$ death, 9\% myocardial infarction, $15 \%$ coronary revascularization). Interestingly, the study cohort consisted of high-risk patients defined with high prevalence of end-stage renal disease $(21 \%)$, diabetes $(48 \%)$, prior myocardial infarction $(25 \%)$, and prior coronary revascularization (49\%). However, it appears that $437(63 \%)$ patients had a normal first study. In particular, in 399 patients both MPI studies were normal. Our group recently performed a meta-analysis of published studies including diabetic patients with known or suspected CAD to assess the predictive value of normal stress MPI. ${ }^{21}$ During a weighted mean follow-up of 36.2 months, the negative predictive value for cardiac death and non-fatal myocardial infarction of normal MPI was 94.92\% [95\% confidence interval (CI) 93.67-96.05], resulting in an estimated annualized event rate after a negative test of $1.60 \%$ (95\% CI 1.21-2.04). Thus, in the study of El-Hajj et al, ${ }^{20}$ a significant number of deaths were probably due to non-cardiac cause, questioning the link between MPI results and outcome. Ideally, competing risk analysis could have given further insights into the prognostic value of serial assessment myocardial perfusion. $^{22}$

\section{WARRANTY PERIOD OF NORMAL MPI STUDY}

El-Hajj et $\mathrm{al}^{20}$ found that only 38 out of 437 patients with normal perfusion on MPI-1 had abnormal perfusion on MPI-2. The authors clearly stated that patients in groups 2 and 3 were significantly older, had more comorbidities, higher prevalence of prior myocardial infarction and coronary revascularization, and were on more cardiovascular medications as compared to group 1, but they did not report if some covariates might predict the switch from normal to abnormal MPI. Instead, any effort to clarify the warranty period of a normal MPI is welcome. It must be outlined that the warranty period of a normal stress MPI varies according to clinical variables and post-stress LVEF. In the study of El-Hajj et al, ${ }^{20} 193$ (28\%) patients, proportionately distributed among the 3 groups, had a drop in LVEF $\geq 5 \%$. When the drop in LVEF was considered in the multivariate Cox model, it was independently associated with the primary outcome [hazard ratio (HR) 1.5, 95\% CI 1.1-2.1, $P=.01$ ]. These results agree with those reported by Acampa et al ${ }^{23}$ who evaluated the relationship between diabetes and temporal characteristics of cardiac risk at long-term follow-up in a propensity score-matched cohort of diabetic and nondiabetic patients with normal MPI. After matching, clinical characteristics were comparable in 260 diabetic and 260 non-diabetic patients. All patients were followed for at least 1 year (median 53 months). End-point events were cardiac death or nonfatal myocardial infarction. At Cox multivariable analysis, diabetes and post-stress LVEF $\leq 45 \%$ were independent predictors of events. At parametric analysis, non-diabetic patients with poststress LVEF $>45 \%$ remained at low risk for the entire length of follow-up, while the highest probability of events and the major risk acceleration was observed in patients with diabetes and post-stress LVEF $\leq 45 \%$. Thus, the warranty period of a normal stress MPI varies according to diabetic status and post-stress LVEF.

\section{CHALLENGES OF LONGITUDINAL STUDIES}

Longitudinal study refers to investigations where participant outcomes and possibly treatments or exposures are collected at multiple follow-up times, yielding repeated measurements on each subject. In longitudinal clinical study, it is also common to observe relevant events, generating time-to-event data. If the interest is to analyze the longitudinal outcome response variable with dropout at the time of event, longitudinal data analysis is performed. Unlike cross-sectional designs, where 

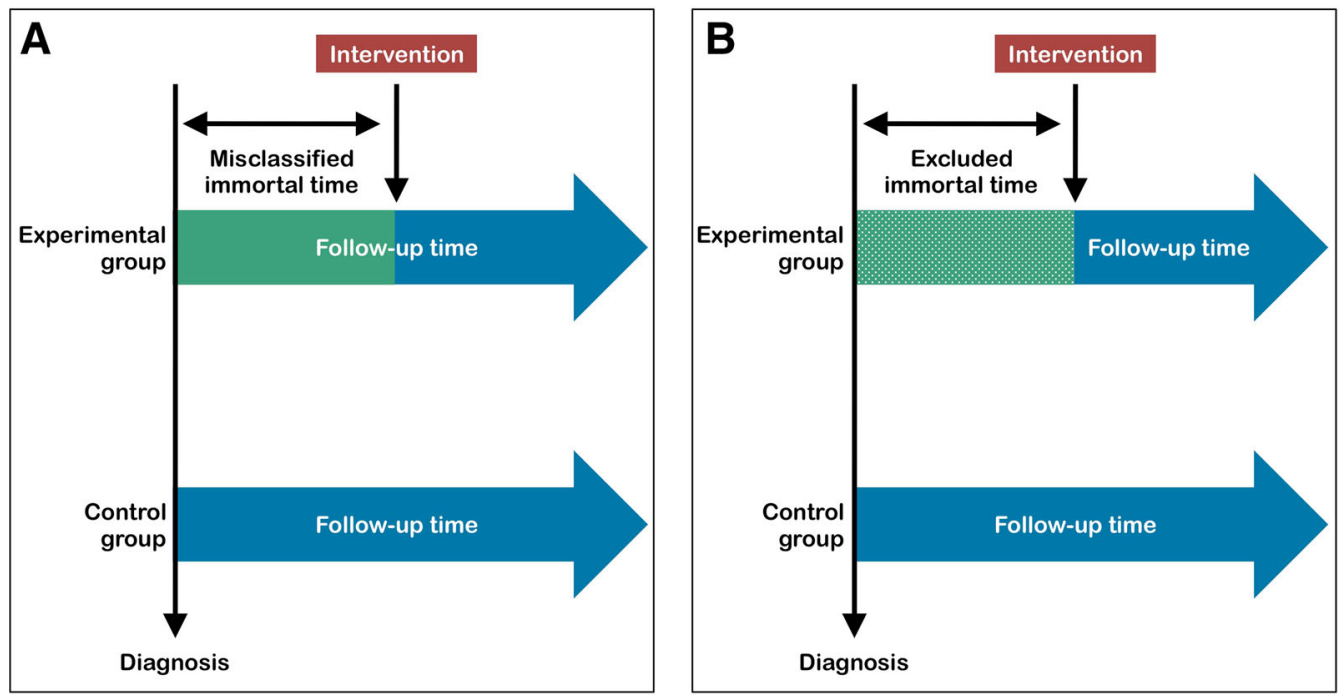

Figure 1. Types of immortal time bias. The period between entry in the study and date of first exposure (to a drug, a procedure to a diagnostic test), during which death has not occurred, is either misclassified (A) or simply excluded and not accounted for in the analysis (B). Both "misclassified immortal time" (A) and "excluded immortal time" lead to a bias in favor of the intervention group.

observations from study subjects are available only at a single time point, individuals in longitudinal or cohort studies are assessed repeatedly over time. By taking advantages of multiple snapshots of a group over time, data from longitudinal studies capture both betweenindividual differences and within-individual dynamics, affording the opportunity to study more complicated biological, psychological, and behavioral hypotheses than their cross-sectional counterparts. However, longitudinal data present multiple methodological challenges in study designs and data analyses, such as the correlation among the repeated responses of the same subject, heterogeneous variability (the variance of the response changes over the study), and the presence of missing data. ${ }^{24}$ Approaches to modeling continuous longitudinal data are the analysis of response profiles, linear mixedeffects models, and generalized estimating equations. Another problem is that only patients who survived to further observations may be included in the analysis (an example of informative censoring). This is more evident in retrospective study and is known as "immortal time," a period of follow-up during which, by design, death or the study outcome cannot occur. ${ }^{25,26}$ This bias may have serious consequences in particular in the evaluation of life-extension benefits of therapy (Figure 1). Several statistical approaches have been suggested to avoid this source of bias and these include Cox's proportional hazards regression with time-varying covariates, a modified form of the Kaplan-Meier analysis, and the Poisson regression. ${ }^{27}$ More recently, joint modeling of longitudinal and survival data has been proposed to investigate the relationship between a repeatedly measured marker, subject to measurement error, and the time to an event of interest. ${ }^{28}$

\section{FUTURE DIRECTIONS}

It should be noted that in trials using MPI to assess the effects of therapy, serial imaging would be stronger if at least moderate ischemia is an inclusion criterion, exceeding the variability of MPI and thus assuring that the enrolled patients actually have ischemia. ${ }^{19}$ FarzanehFar et $\mathrm{al}^{29}$ identified 1425 consecutive patients with angiographically documented CAD who underwent 2 serial MPI scans within a 36-month time frame. They found that ischemia worsening is an independent predictor of death or myocardial infarction, resulting in significantly improved risk reclassification when added to previously known predictors. Despite this finding, the authors concluded that their results could not be used as justification for performing serial MPI scans and that randomized prospective trials are required before any such recommendations can be proposed. The ongoing International Study of Comparative Health Effectiveness With Medical and Invasive Approaches (ISCHEMIA) Trial attempts to demonstrate the extent to which an angiographic-driven strategy for higher risk stable ischemic heart disease patients with moderate-severe ischemia will or will not improve clinical outcomes. ${ }^{4}$ This trial will be completed in $\sim 2019$. In the meantime, the data of El-Hajj et $\mathrm{al}^{20}$ further suggest that if a patient has had 2 consecutive MPI studies performed for 
appropriate clinical reasons, the information regarding perfusion change may be used to improve prognostication and can guide clinical practice.

\section{Conflict of interest}

The authors have indicated that they have no financial conflict of interest.

\section{References}

1. Hachamovitch R. What should we expect in a prognosis study in 2012? J Nucl Cardiol 2012;19:883-6.

2. Shaw LJ, Hage FG, Berman DS, Hachamovitch R, Iskandrian A. Prognosis in the era of comparative effectiveness research: Where is nuclear cardiology now and where should it be? J Nucl Cardiol 2012;19:1026-43.

3. Hachamovitch R, Rozanski A, Shaw LJ, Stone GW, Thomson LE, Friedman JD, et al. Impact of ischaemia and scar on the therapeutic benefit derived from myocardial revascularization vs. medical therapy among patients undergoing stress-rest myocardial perfusion scintigraphy. Eur Heart J 2011;32:1012-24.

4. Phillips LM, Hachamovitch R, Berman DS, Iskandrian AE, Min $\mathrm{JK}$, Picard MH, et al. Lessons learned from MPI and physiologic testing in randomized trials of stable ischemic heart disease: COURAGE, BARI 2D, FAME, and ISCHEMIA. J Nucl Cardiol 2013;20:969-75

5. Petretta M, Acampa W, Daniele S, Petretta MP, Nappi C, Assante $\mathrm{R}$, et al. Transient ischemic dilation in SPECT myocardial perfusion imaging for prediction of severe coronary artery disease in diabetic patients. J Nucl Cardiol 2013;20:45-52.

6. Abidov A, Germano G, Hachamovitch R, Berman DS. Gated SPECT in assessment of regional and global left ventricular function: Major tool of modern nuclear imaging. J Nucl Cardiol 2006;13:261-79.

7. Petretta M, Acampa W, Daniele S, Petretta MP, Plaitano M, Cuocolo A. Transient ischemic dilation in patients with diabetes mellitus: prognostic value and effect on clinical outcome after coronary revascularization. Circ Cardiovasc Imaging 2013;6:908-15.

8. Shaw LJ, Berman DS, Maron DJ, Mancini GB, Hayes SW, Hartigan PM, COURAGE Investigators, et al. Optimal medical therapy with or without percutaneous coronary intervention to reduce ischemic burden: results from the Clinical Outcomes Utilizing Revascularization and Aggressive Drug Evaluation (COURAGE) trial nuclear substudy. Circulation 2008;117:1283-91.

9. Shaw LJ, Cerqueira MD, Brooks MM, Althouse AD, Sansing VV, Beller GA, et al. Impact of left ventricular function and the extent of ischemia and scar by stress myocardial perfusion imaging on prognosis and therapeutic risk reduction in diabetic patients with coronary artery disease: Results from the Bypass Angioplasty Revascularization Investigation 2 Diabetes (BARI 2D) trial. J Nucl Cardiol 2012;19:658-69.

10. Mahmarian JJ, Dakik HA, Filipchuk NG, Shaw LJ, Iskander SS, Ruddy TD, INSPIRE Investigators, et al. An initial strategy of intensive medical therapy is comparable to that of coronary revascularization for suppression of scintigraphic ischemia in high-risk but stable survivors of acute myocardial infarction. J Am Coll Cardiol 2006;48:2458-67.

11. Wackers FJ, Chyun DA, Young LH, Heller GV, Iskandrian AE, Davey JA, Detection of Ischemia in Asymptomatic Diabetics (DIAD) Investigators, et al. Resolution of asymptomatic myocardial ischemia in patients with type 2 diabetes in the Detection of
Ischemia in Asymptomatic Diabetics (DIAD) study. Diabetes Care 2007;30:2892-8.

12. Ghimire G, Hage FG, Heo J, Iskandrian AE. Regadenoson: A focused update. J Nucl Cardiol 2013;20:284-8.

13. Mahmarian JJ, Peterson LE, Xu J, Cerqueira MD, Iskandrian AE, Bateman TM, et al. Regadenoson provides perfusion results comparable to adenosine in heterogeneous patient populations: A quantitative analysis from the ADVANCE MPI trials. J Nucl Cardiol 2015;22:248-61.

14. Iqbal FM, Hage FG, Ahmed A, Dean PJ, Raslan S, Heo J, et al. Comparison of the prognostic value of normal regadenoson with normal adenosine myocardial perfusion imaging with propensity score matching. JACC Cardiovasc Imaging 2012;5:1014-21.

15. Hage FG, Ghimire G, Lester D, Mckay J, Bleich S, El-Hajj S, Iskandrian AE. The prognostic value of regadenoson myocardial perfusion imaging. J Nucl Cardiol 2015. doi:10.1007/s12350-014-0050-y.

16. Cintron G, Johnson G, Francis G, Cobb F, Cohn JN. Prognostic significance of serial changes in left ventricular ejection fraction in patients with congestive heart failure. The V-HeFT VA Cooperative Studies Group. Circulation 1993;87:VI17-23.

17. Raggi P, Cooil B, Shaw LJ, Aboulhson J, Takasu J, Budoff M, et al. Progression of coronary calcium on serial electron beam tomographic scanning is greater in patients with future myocardial infarction. Am J Cardiol 2003;92:827-9.

18. Kuznetsova T, Thijs L, Knez J, Cauwenberghs N, Petit T, Gu YM, et al. Longitudinal changes in left ventricular diastolic function in a general population. Circ Cardiovasc Imaging 2015;8:e02882.

19. Iskandrian AE, Hage FG, Shaw LJ, Mahmarian JJ, Berman DS. Serial myocardial perfusion imaging: Defining a significant change and targeting management decisions. JACC Cardiovasc Imaging 2014;7:79-96

20. El Hajj S, AlJaroudi WA, Farag A, Bleich S, Manaoragada P, Iskandrian $\mathrm{AE}$, et al. Effect of changes in perfusion defect size during serial regadenoson myocardial perfusion imaging on cardiovascular outcomes in high-risk patients. J Nucl Cardiol 2015. doi:10.1007/s12350-015-0174-8.

21. Acampa W, Cantoni V, Green R, Maio F, Daniele S, Nappi C, et al. Prognostic value of normal stress myocardial perfusion imaging in diabetic patients: A meta-analysis. J Nucl Cardiol 2014;21:893-902.

22. Wolbers M, Koller MT, Stel VS, Schaer B, Jager KJ, Leffondré K, et al. Competing risks analyses: Objectives and approaches. Eur Heart J 2014;35:2936-41.

23. Acampa W, Petretta M, Cuocolo R, Daniele S, Cantoni V, Cuocolo A. Warranty period of normal stress myocardial perfusion imaging in diabetic patients: A propensity score analysis. J Nucl Cardiol 2014;21:50-6.

24. Fitzmaurice GM, Ravichandran C. A primer in longitudinal data analysis. Circulation 2008;118:2005-10.

25. Shariff SZ, Cuerden MS, Jain AK, Garg AX. The secret of immortal time bias in epidemiologic studies. J Am Soc Nephrol 2008;19:841-3.

26. Liu J, Weinhandl ED, Gilbertson DT, Collins AJ, St Peter WL. Issues regarding 'immortal time' in the analysis of the treatment effects in observational studies. Kidney Int 2012;81:341-50.

27. Webster NR. Professors live longer than doctors: Immortality bias in survival analysis. Br J Anaesth 2011;106:161-3.

28. Crowther MJ, Abrams KR, Lambert PC. Flexible parametric joint modelling of longitudinal and survival data. Stat Med 2012;31:4456-71.

29. Farzaneh-Far A, Phillips HR, Shaw LK, Starr AZ, Fiuzat M, O'Connor CM, et al. Ischemia change in stable coronary artery disease is an independent predictor of death and myocardial infarction. JACC Cardiovasc Imaging 2012;5:715-24. 